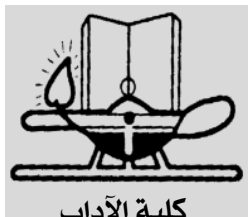

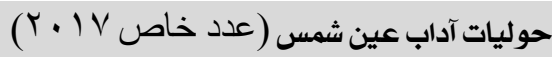
http://www.aafu.journals.ekb.eg

(دورية علمية محكمةة)

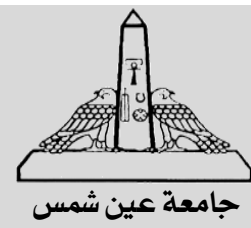

هوقف المدثيدن هن احتجاج نهاة العربية بنصوص القرآن الكريم.

* أمة الخالق محمد المرصد

مدرس في قسم اللغة العربية وطر ائق تدريسها/ كلية التربية/ جامعة صنعاء/ الجمهورية اليمنية.

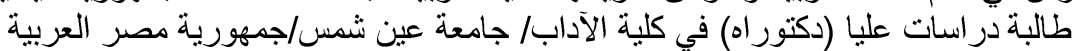

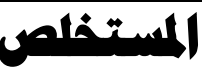

هذا البحث يتتاول موقف المحدثين من احتجاج نحاة العربية بنصوص القرآن الكريم وقر اءاته، وقد مهدت لهذه الدراسة بموقف النحاة القدماء من القراءات القر آنية، وبينت فيه

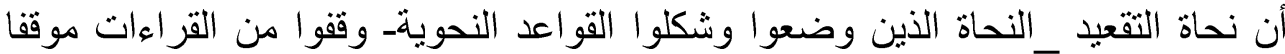

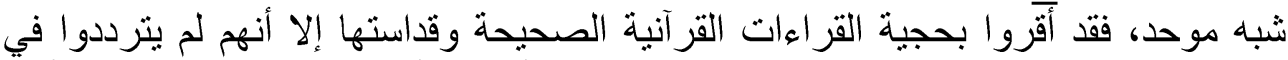

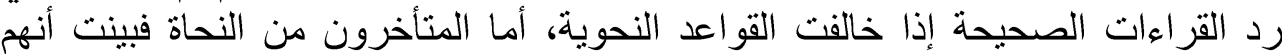

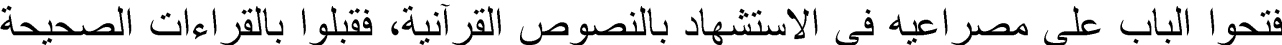

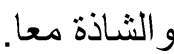

وتناولت في هذا البحث أيضا موقف المحدثين من احتجاج نحاة العربية بنصوص أنصاء

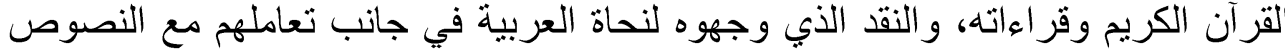

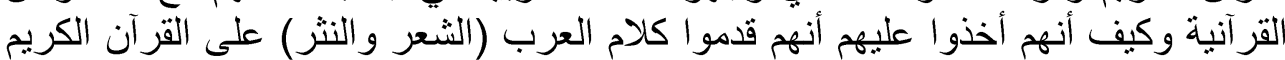

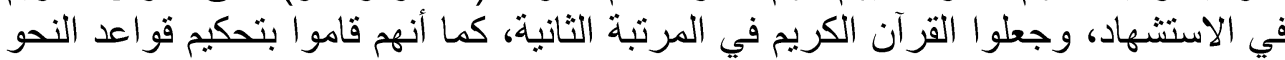

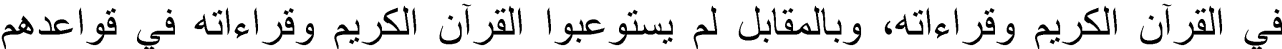
النحوية، كذلك أخذوا عليهم ردهم للقر اءات القر آنية الصحيحة التي خالفت قو اعدهم النحوية. 


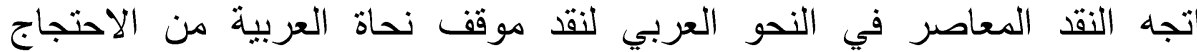

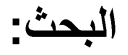
بالقراءات القرآنية، إذ رأى جمع من المعاصرين أن ثمة جوانب قصور أصابت النصائ النحو

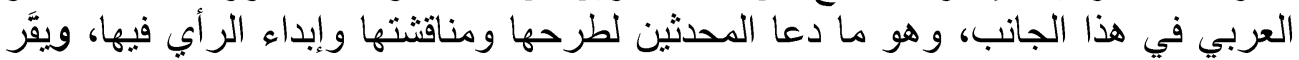

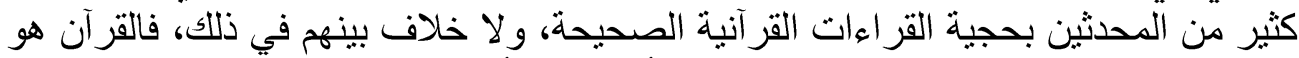
النص الموثق توثيقا عاليا، فلا يخالطه شك أو ريب، أخذ منه نحاة العربية، فكانت بداية

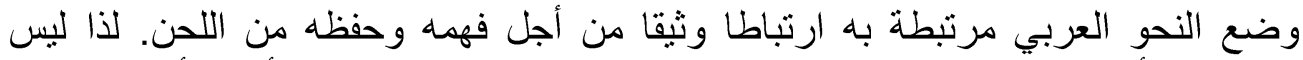

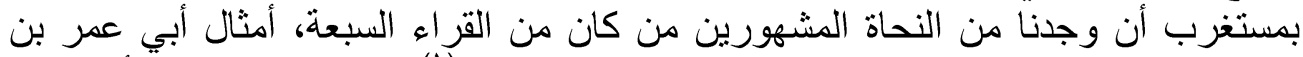

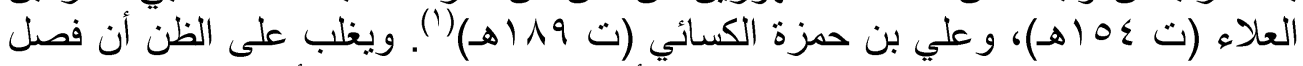

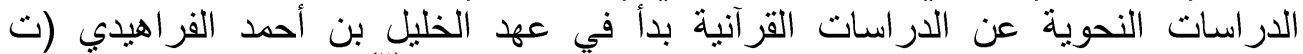

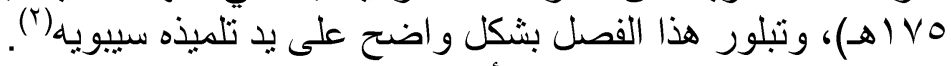

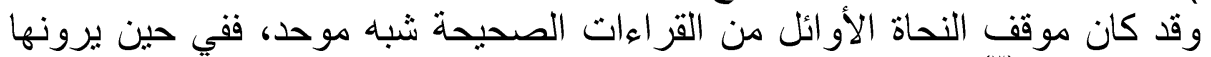

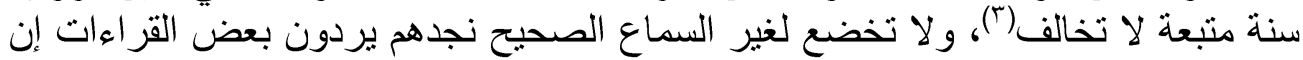

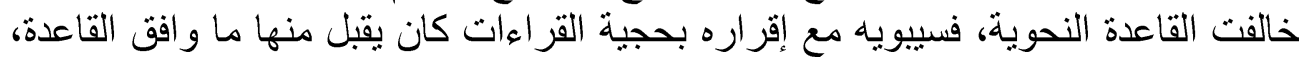

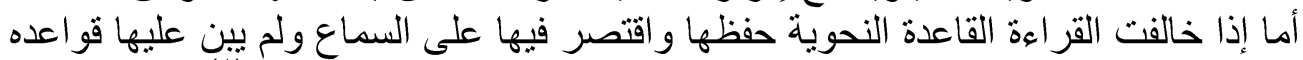

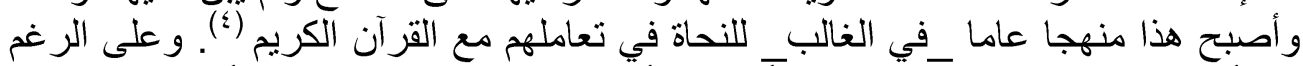

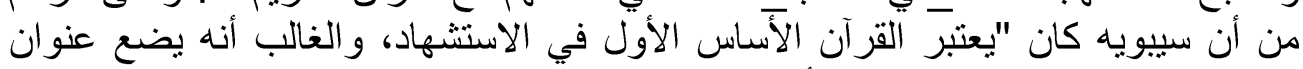

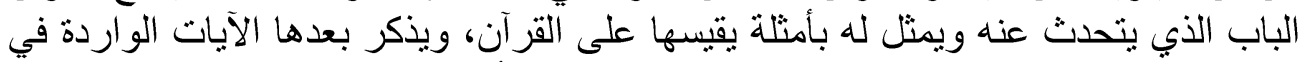

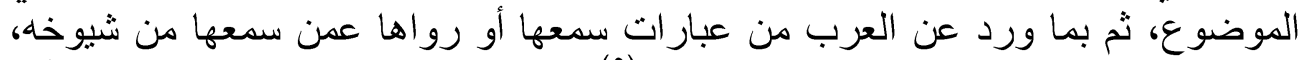

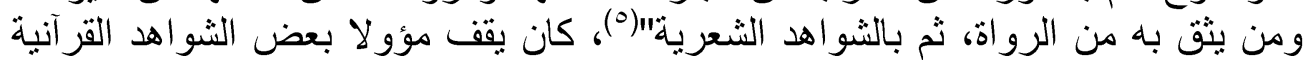

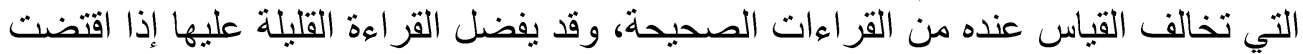

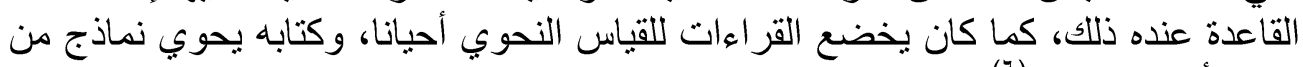

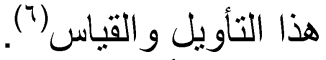

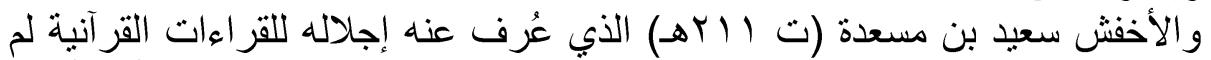

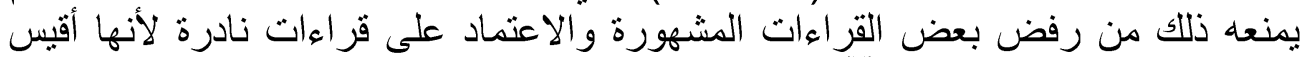

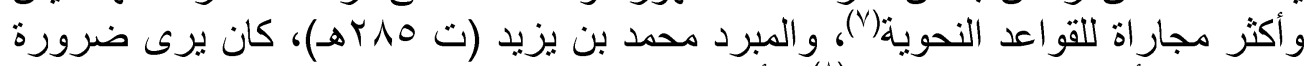

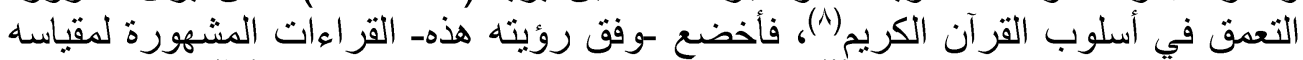

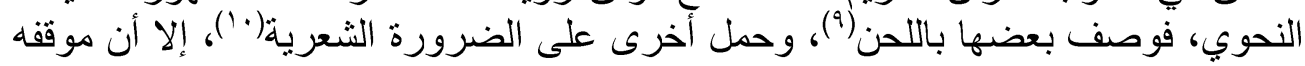

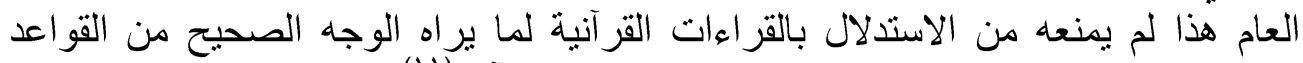

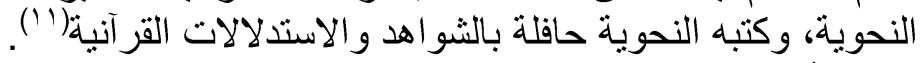

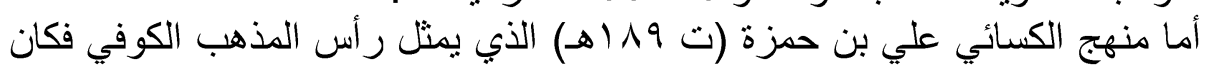

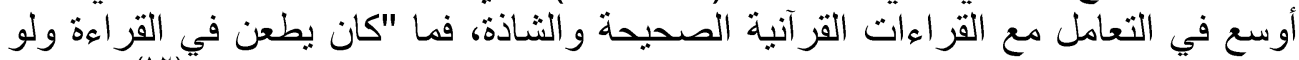

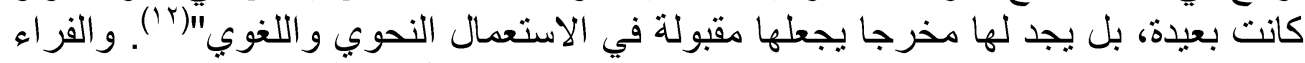

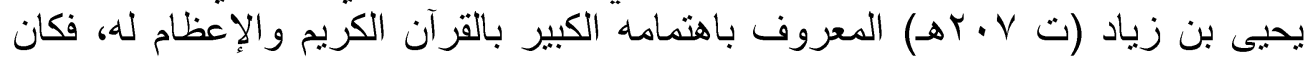

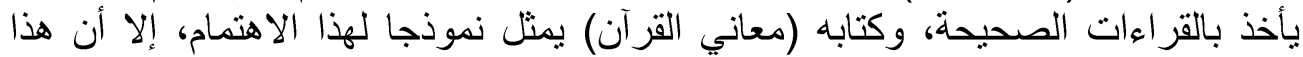

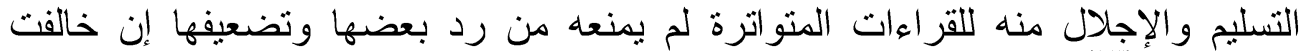

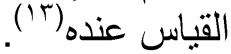
وبالعموم "فالاستشهاد بالقر اءات المتواترة غبر المبات المخالفة للقباس سار عليه البصريون

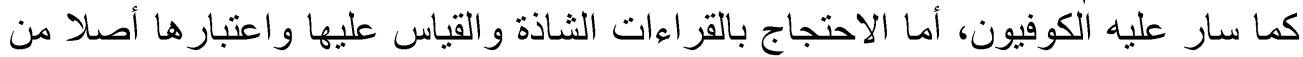

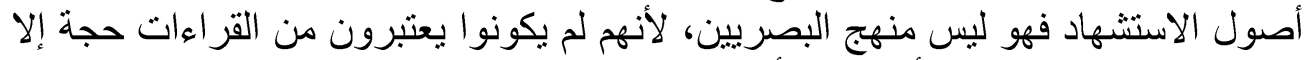

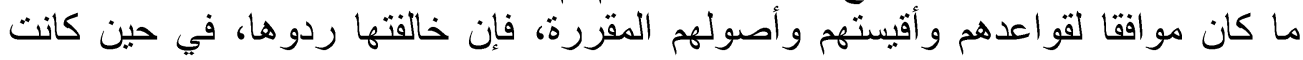




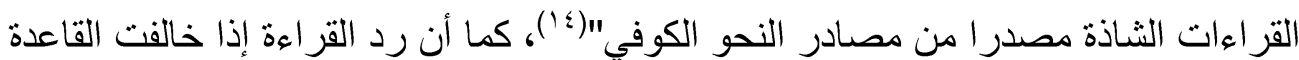

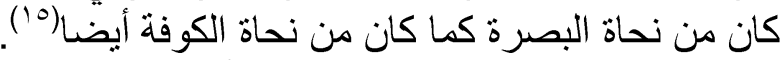

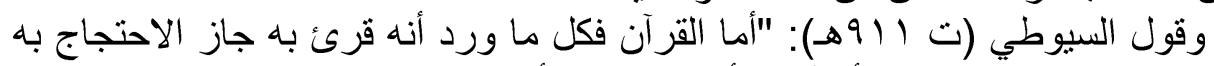

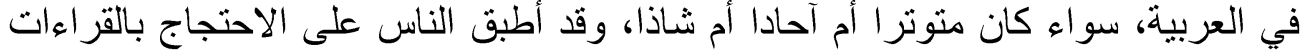

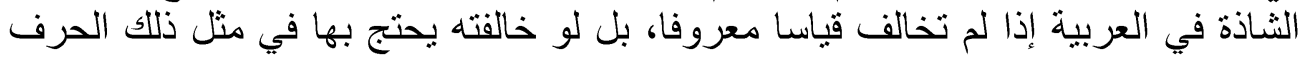

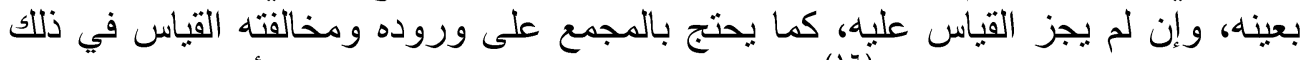

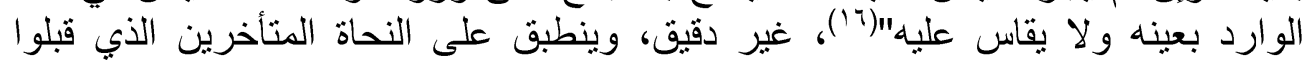

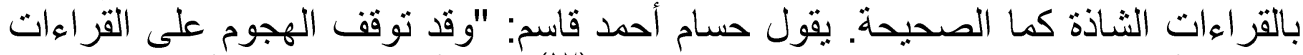

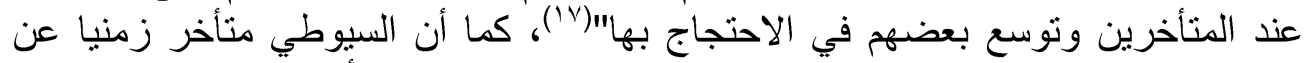

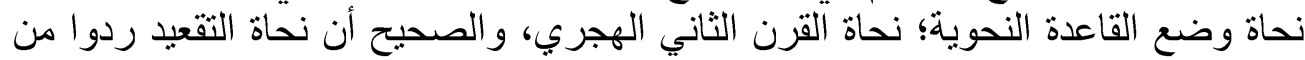
القر اعات الصحيحة كما ردو الصاعة الثناذة.

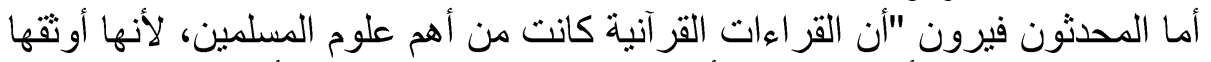

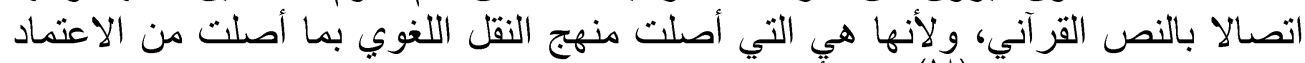

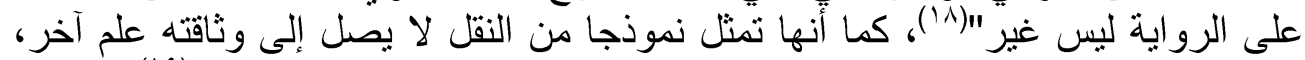

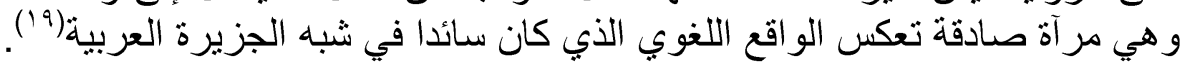

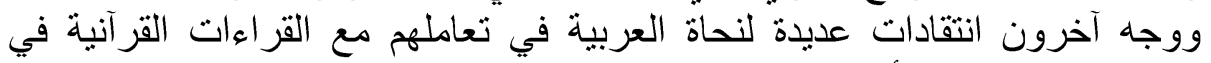

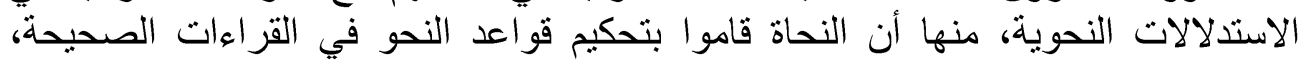

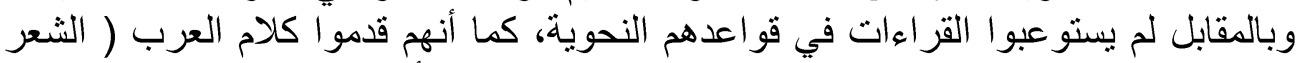

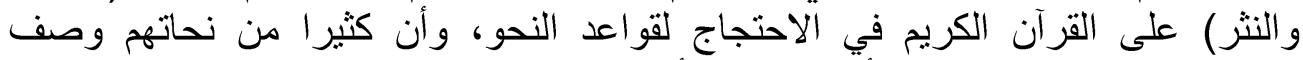

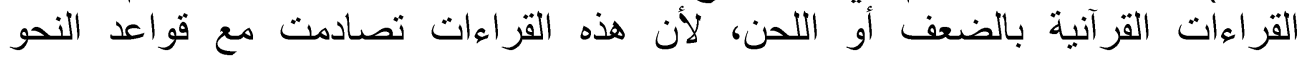

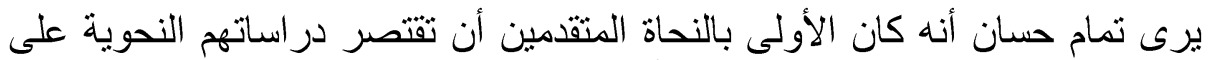

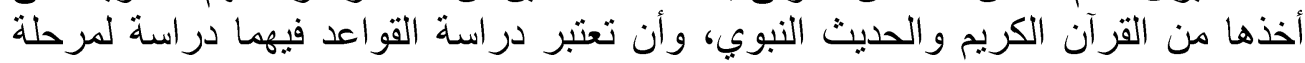

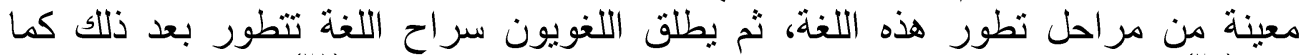

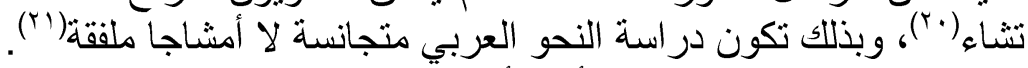

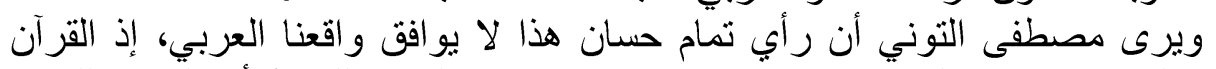

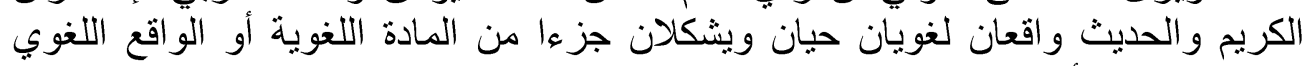

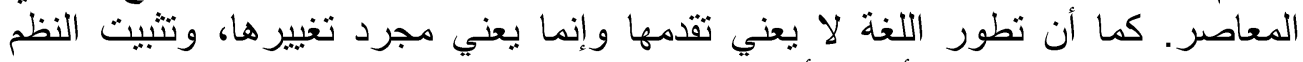

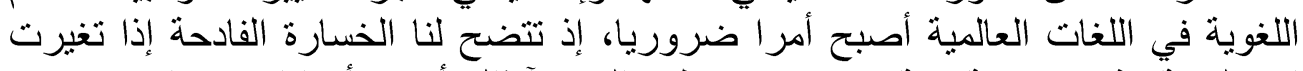

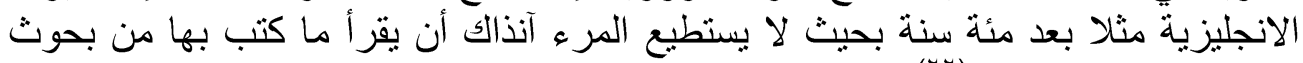
علمية في مرحلة سابقة.

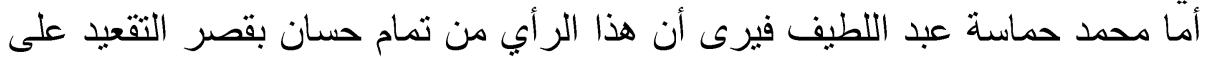

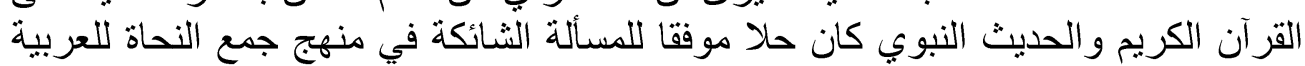

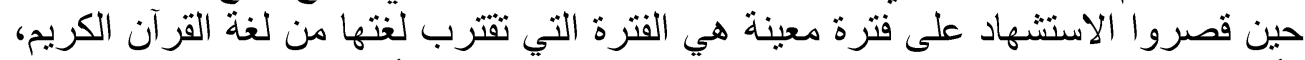

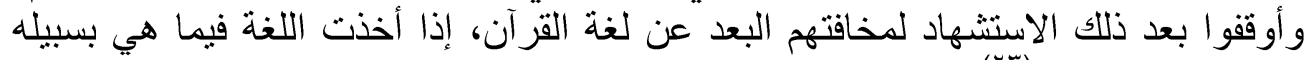

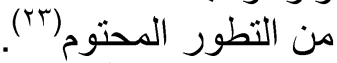

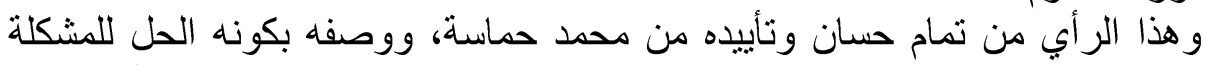

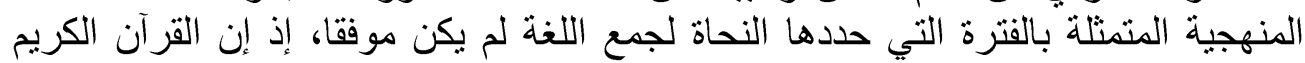

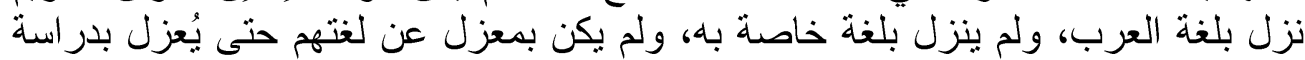




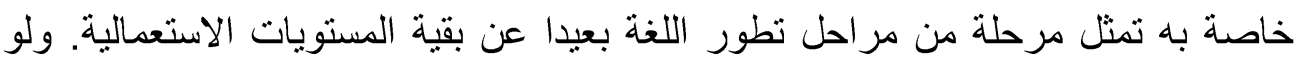

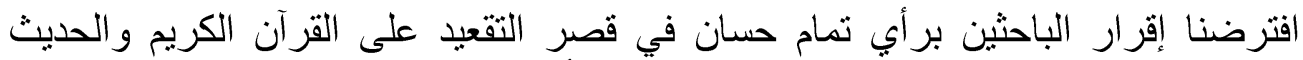
النبوي دون بقية المستويات فمعنى ذلك التسليم بمبدأ الفصل بين هذه التئين المستويات الاستعمالية

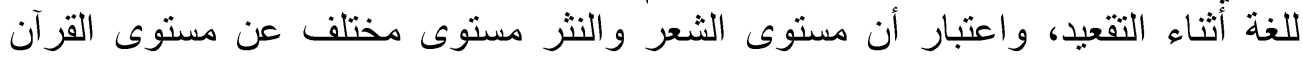

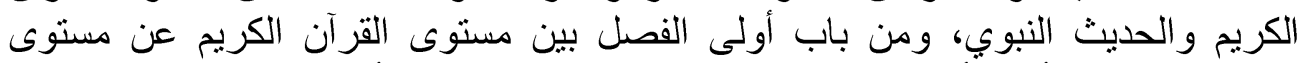

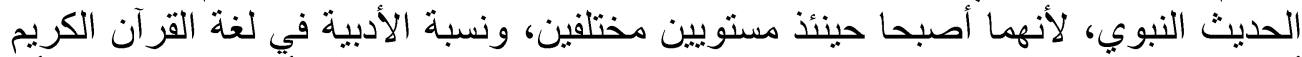

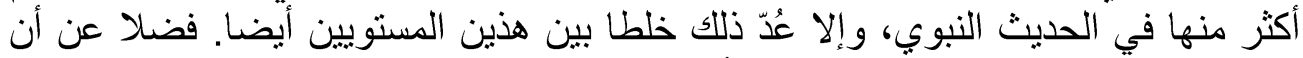

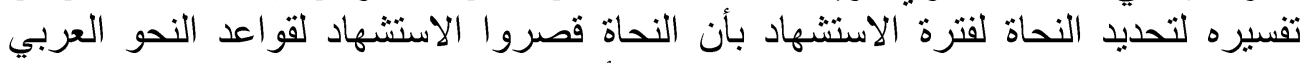

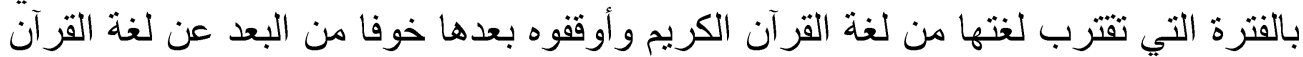

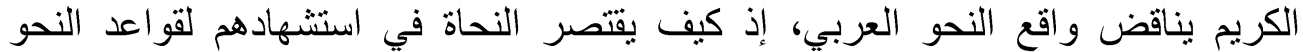

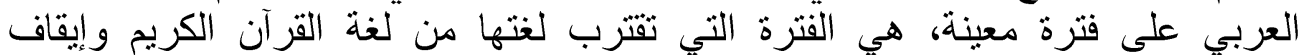

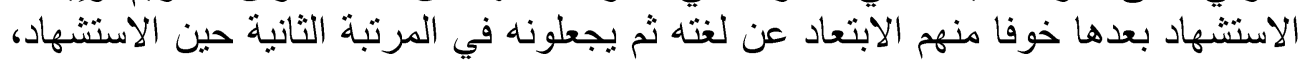

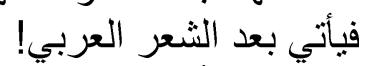

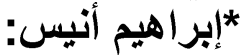

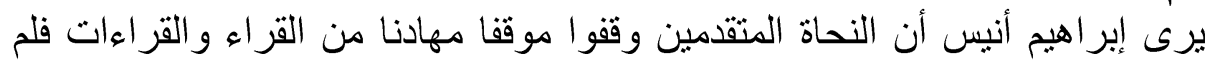

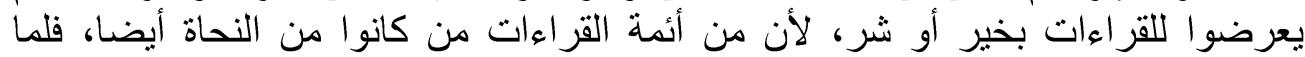

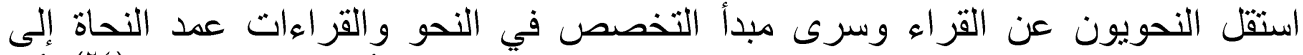

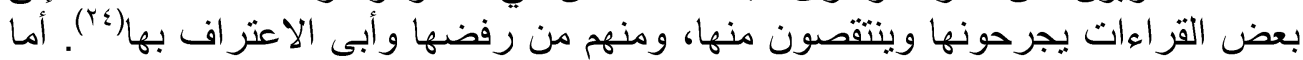

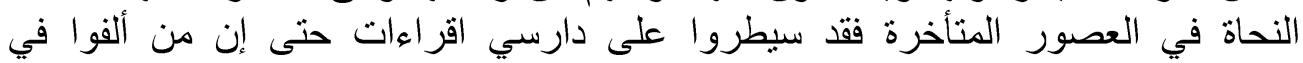

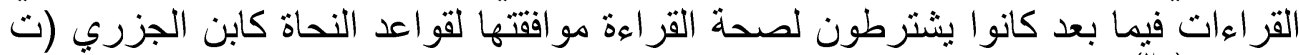
r

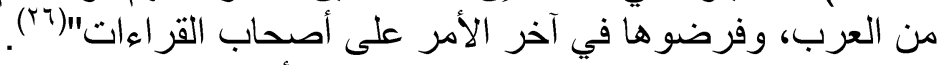

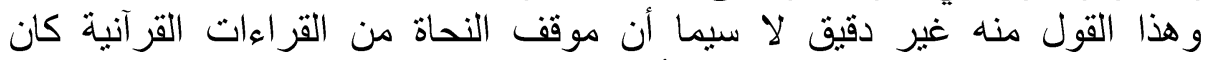

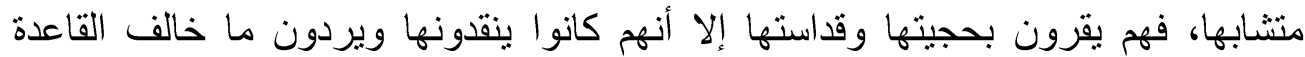
النحوية، فضلا عن أن نحاة التقعيد كانوا بنظرون للقراء التهات بمعبار مختلف عن معيار

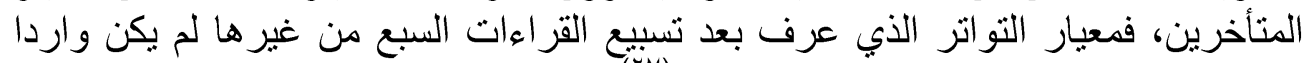

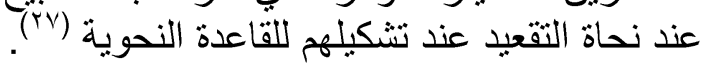

\section{"محمد عيل.}

برى محمد عيد أن النحاة قد صرفوا أنفسه قصدا عن استقراء النص القرآني

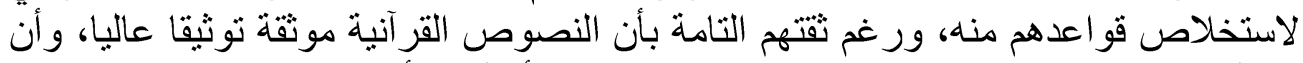

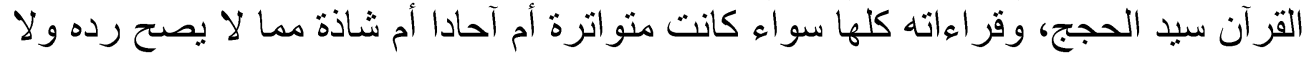

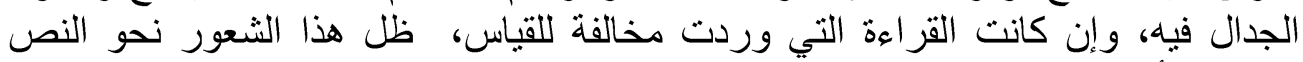

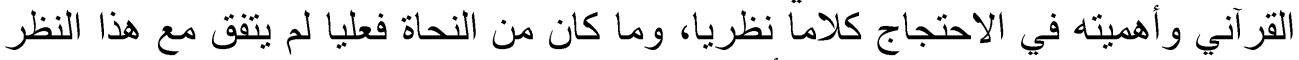

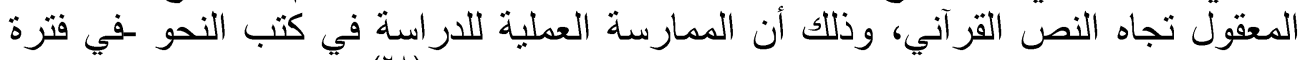

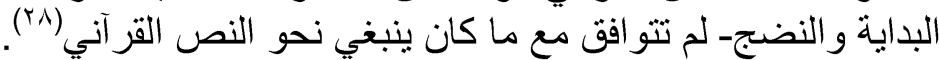

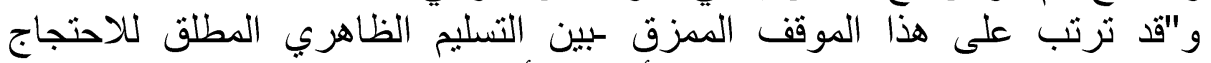

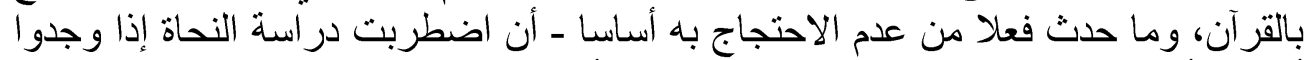

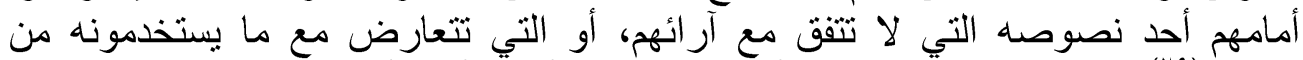

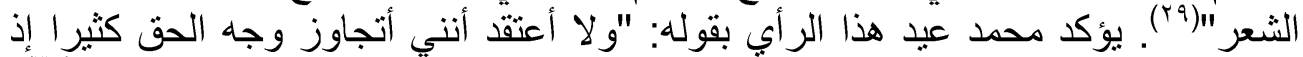

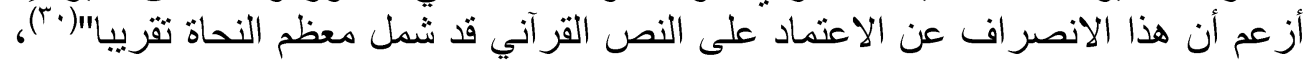


مستدلا في هذا بأن كل كتب الثواهد التي بين أبدينا محشوة بالشعر ، حتى أصبحت لفظة إلته

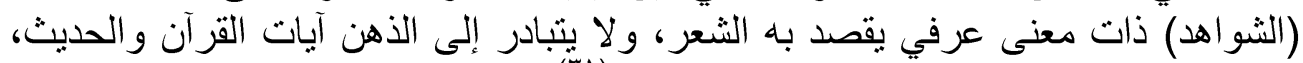

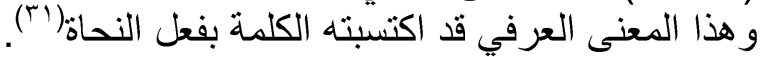

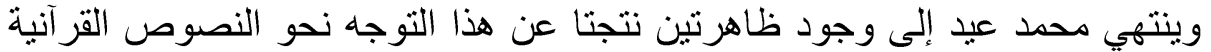

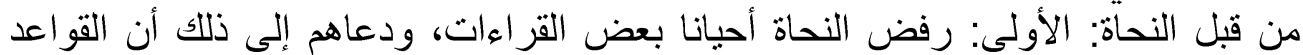

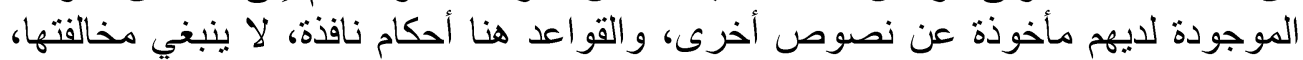
و الخروج على مقتضاها لأي نص، حتى القراءة الواردة التودة الصحيحة السند أحيانا، الثانية:

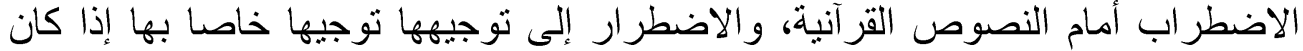

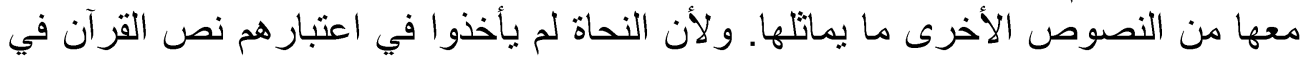

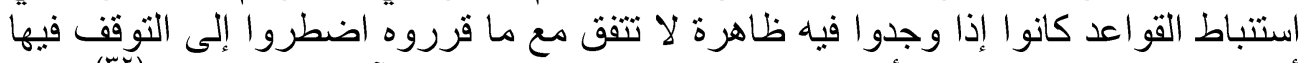

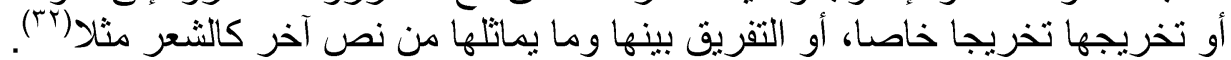

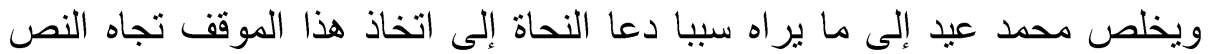

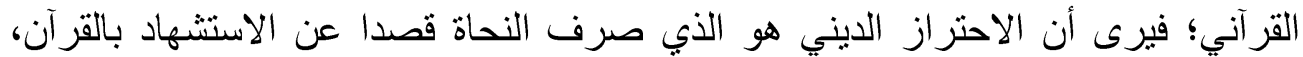

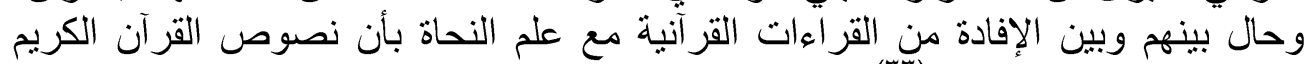

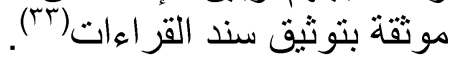
و هذه الملاحظة من محمد عبد، ربما تكون صحيحة وتقفر إحجام النحاة عن كثرة

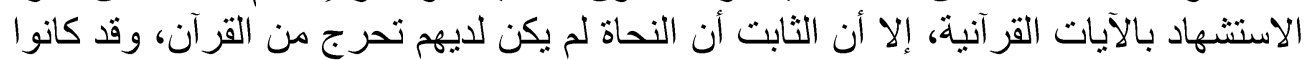
يردون القر اءات حين تخالف المعيار . ولمحمد عبد رأي حيال هذا التحرز من النحاة، إذ برى أن أن "تدخل (العامل الديني) في

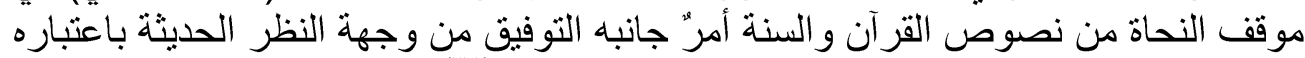

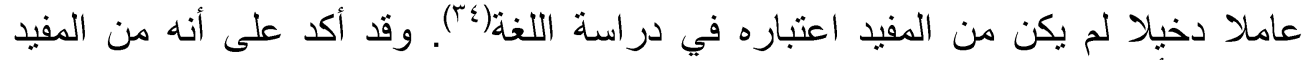

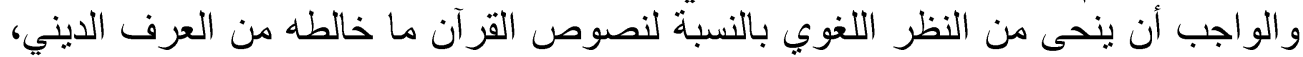

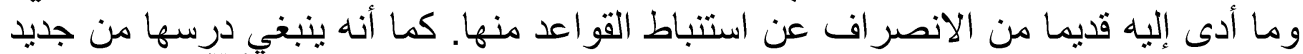

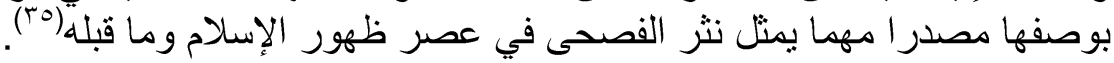

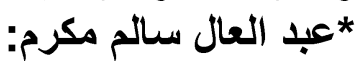

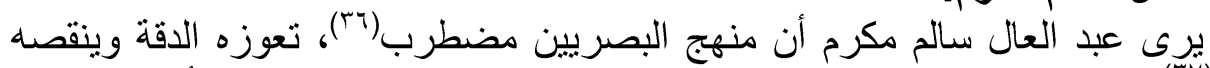

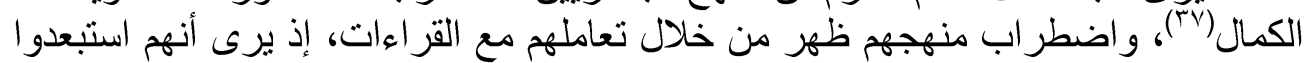

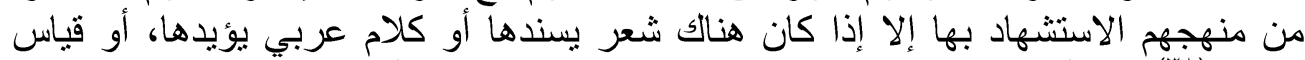

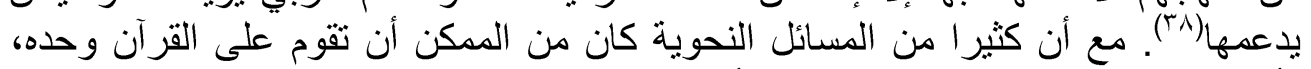

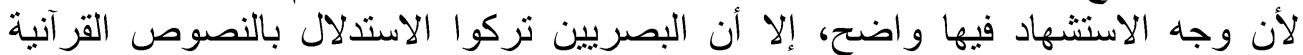

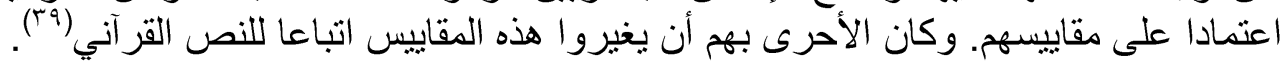

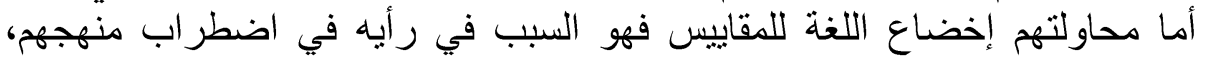

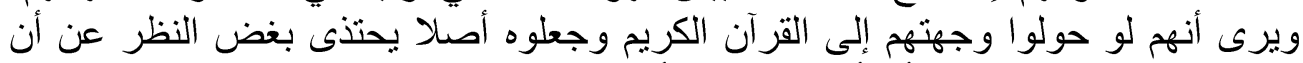

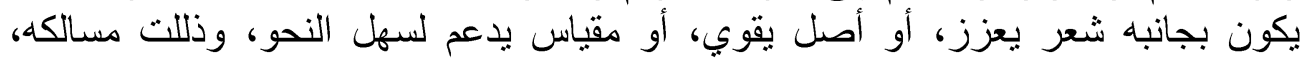

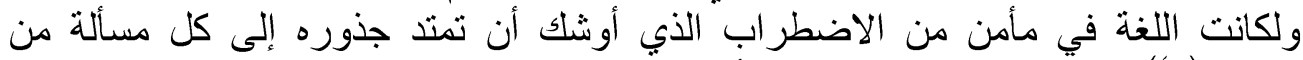

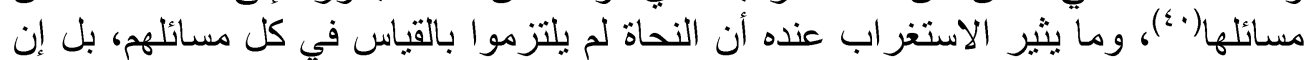

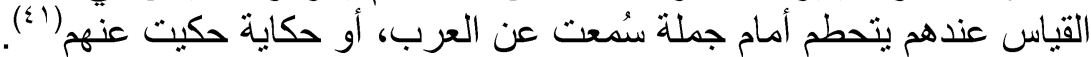

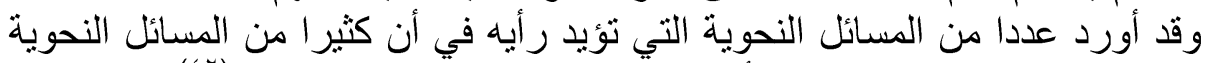

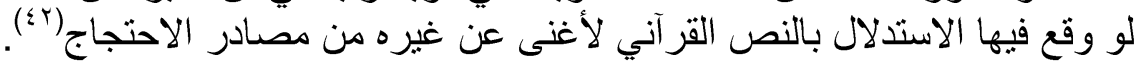




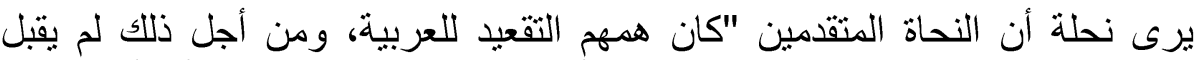

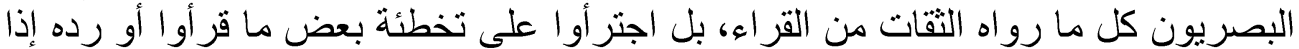

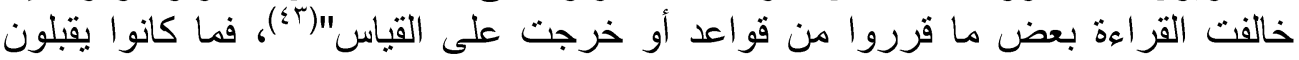

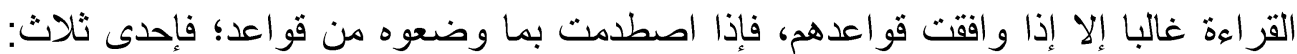

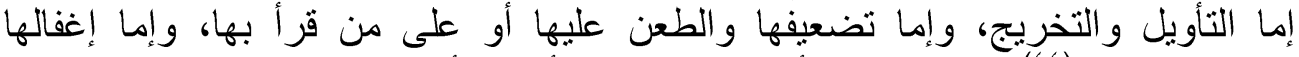

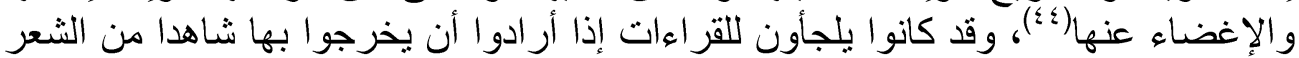
أو من كلام العرب( بالقو اعد النحوية التي استقرت عندهم، ومناط قبول القراعة التهاء عندهم هو وقوفهم على شاهد

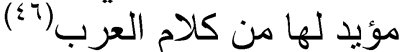

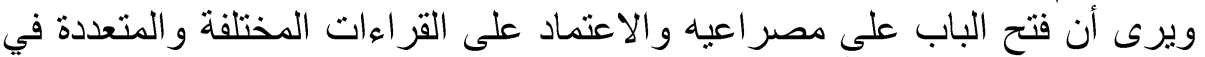

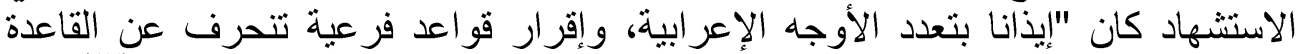

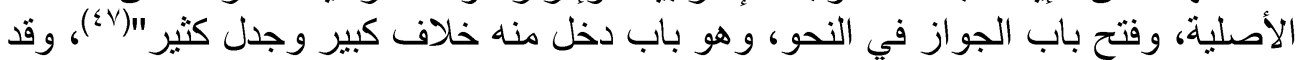

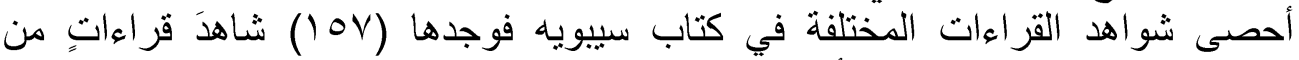

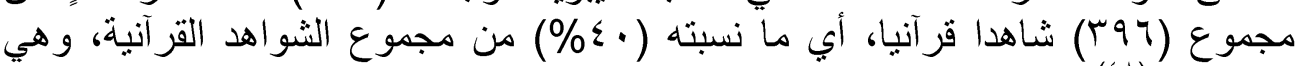

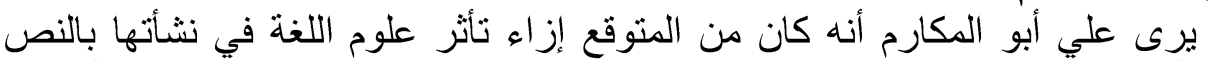

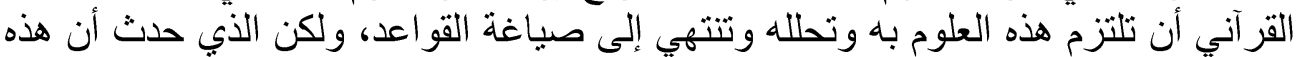

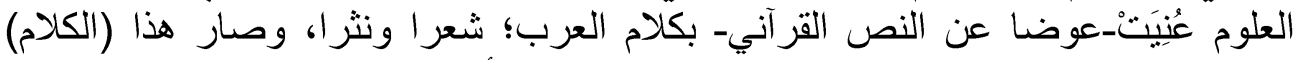

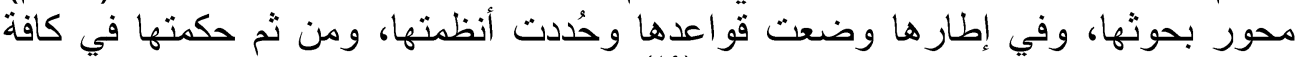

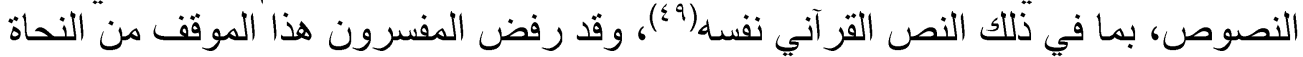

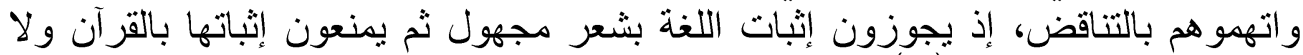

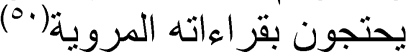
ويرى علي أبو المكارم أيضا أن نحاة هذه المرحلة المبكرة من التقعيد اتخذوا موقفا

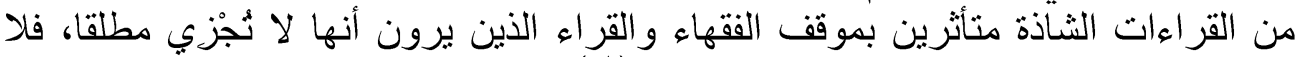

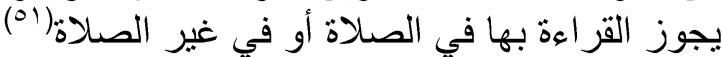
و هذا الر أي منه غير دقيق؛ فقتوى الفقهاء ظهرت متأخرة عن مرحلة تشكيل القاعدة أنها

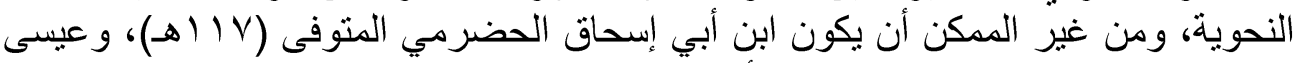

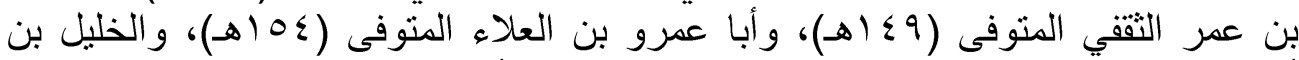

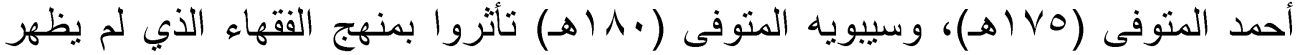
ويترسخ إلا بداية القرن الر ابع الهن الهري.

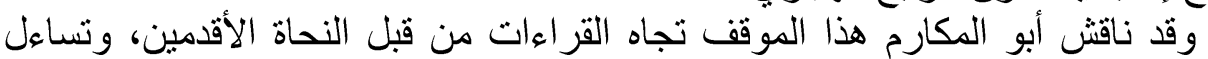

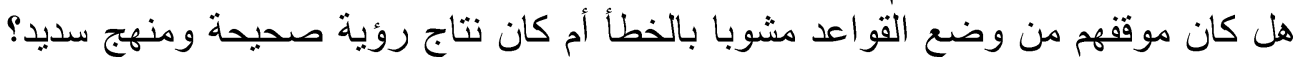

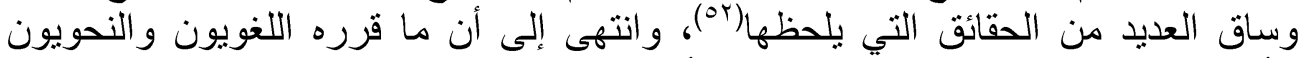

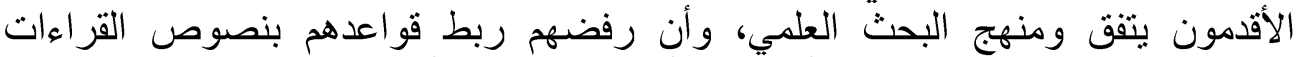

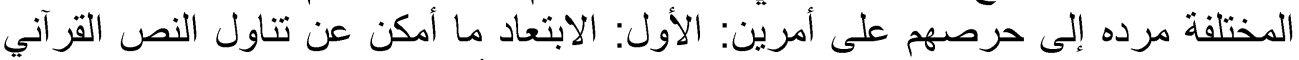

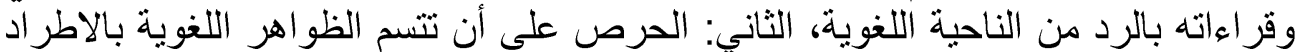


أما النحاة المتأخرون، نحاة القرن الرابع الهجري وما بعده فيرى أبو المكارم أنه قد الداء

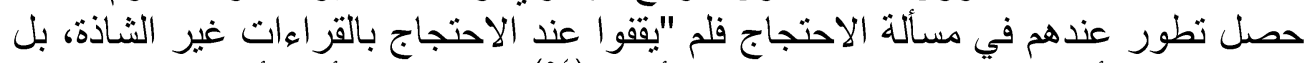

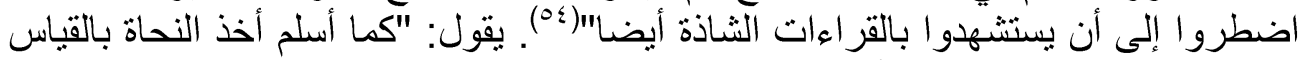

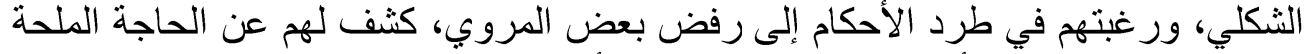

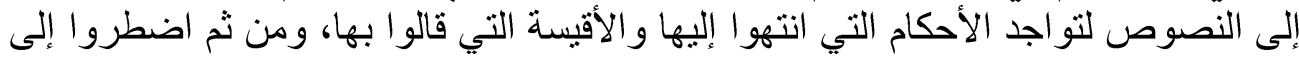

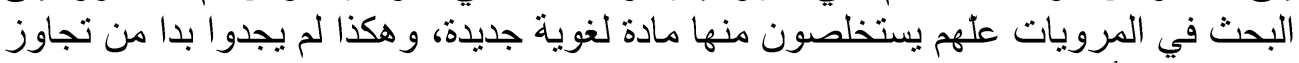

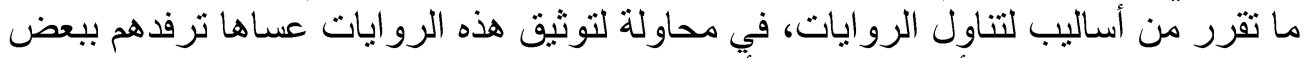

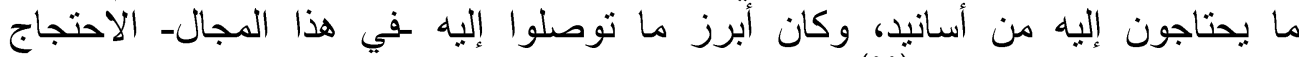
بالقر اءات الثناذة وبالحديث" من (00). وهذا الموقف من النحاة المتأخرين يتفق مع ما ذكره السيوطي من أن كل ما ورد أنه

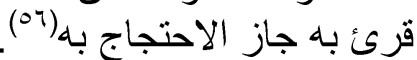

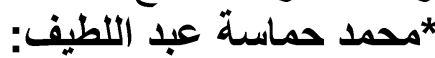

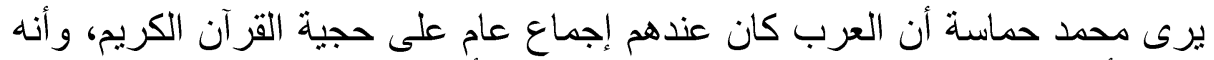

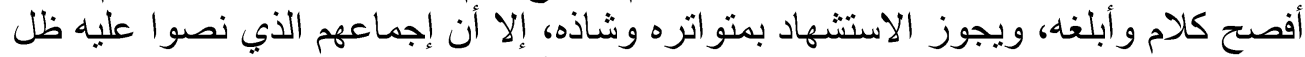
نظريا فقط. وقد دفعهم إلى القول به التحرج الديني، أما من حيث التطبيق التهايق فإنهم لم يلتزموا

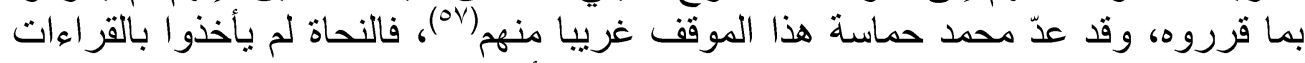

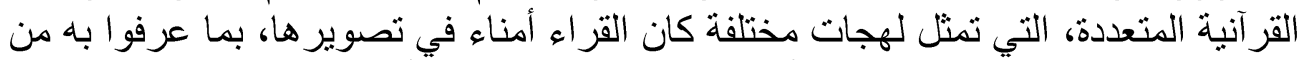

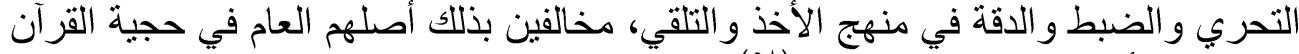

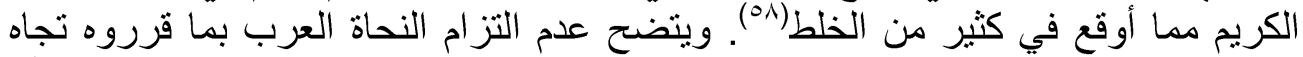

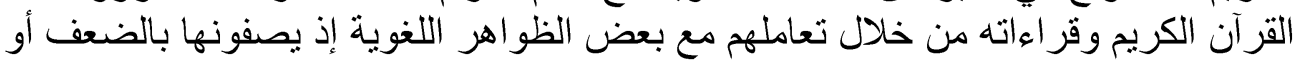

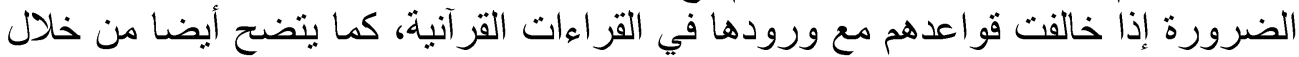

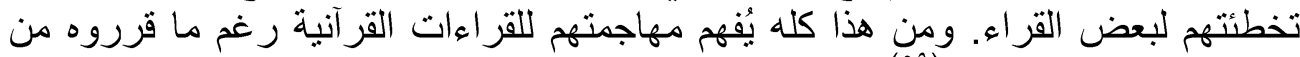

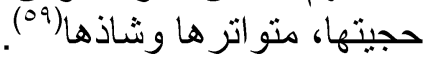

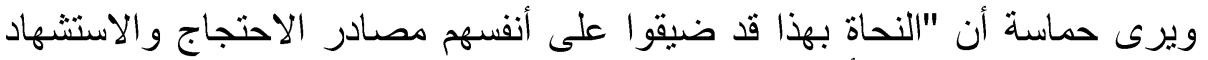

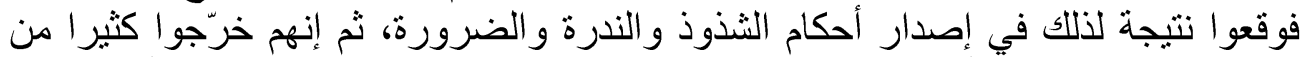

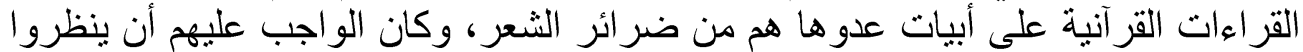

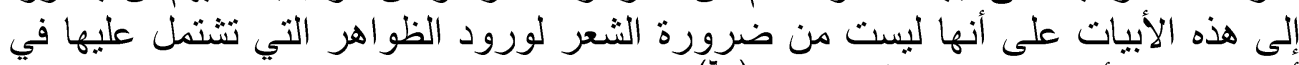

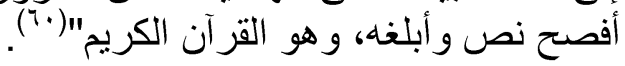


ا ـ رد نحاة العربية (نحاة التقعيد) القراءات الصحيحة إذا خالفت القاعدة النحوية رغم

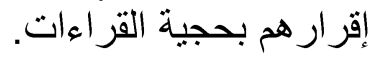

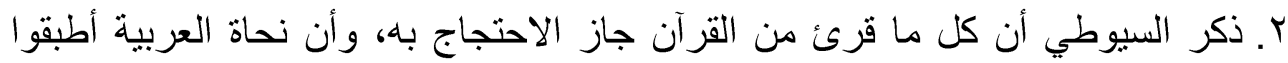

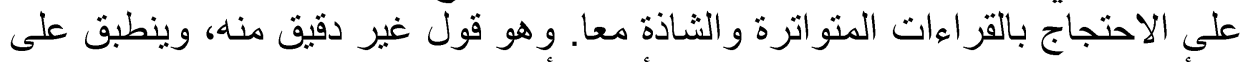

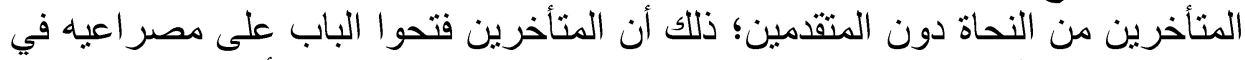

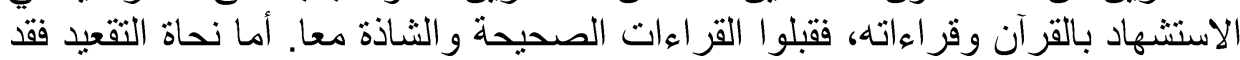

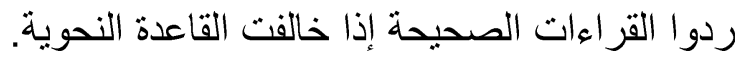

r. وقف المحدثون موقف الناقد من نحاة العربية في تعاملهم مع النصوص النه القرد آنية:

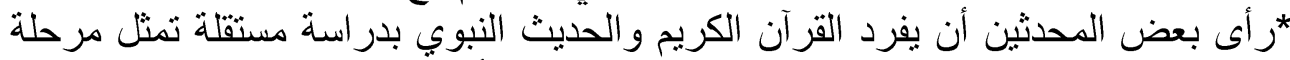

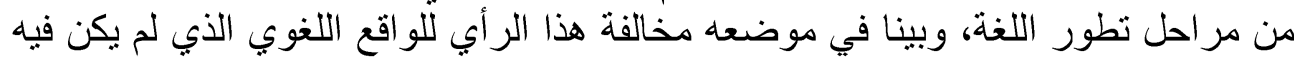

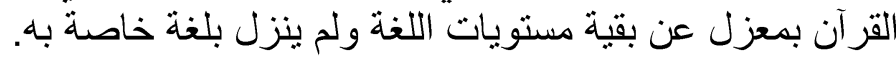

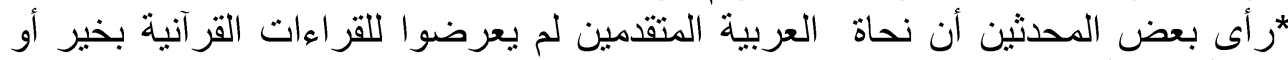

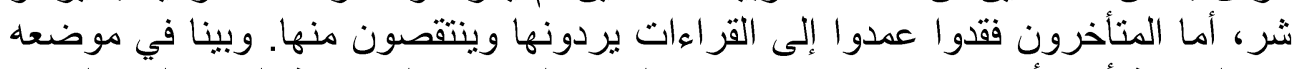

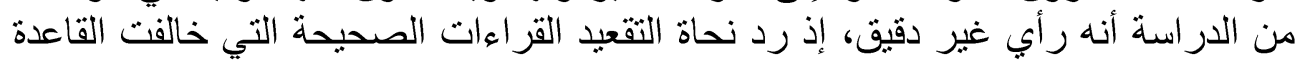
النحوية.

ثرأى بعض المحدثين أن التحرز الديني هو الذي صرف النحاة قصدا عن الاستشهاد

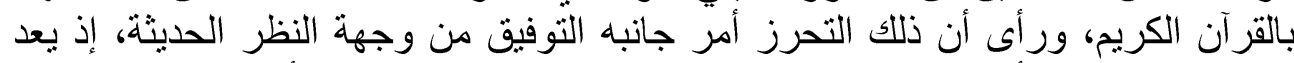

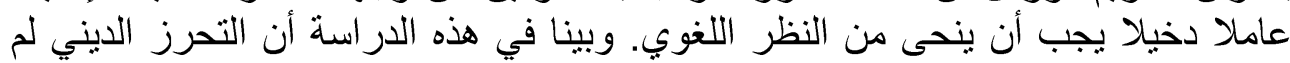

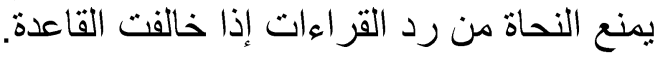




\section{Abstract \\ Arabic contemporary grammarists' point of view of the use of Qura'anic texts and readings as grammatical evidence. \\ By Amaa El- Khalek}

The current study discusses the Arabic contemporary grammarists' point of view of the use of Qura'anic texts and readings as grammatical evidence. The study begins with discussing the old grammarists' point of view of using the Qura'anic texts and readings for grammatical evidence and also mentions how almost all old grammarists had a similar point of view since they asserted the sanctity of the holy Qura'an, but they did not hesitate to reject some of the texts as evidence if they did not match grammatical rules. On the other hand, contemporary grammarists open the door wide for accepting the use of both kinds of texts: those that match grammatical rules and those that do not.

The study focuses on the contemporary grammaraists' point of view of using Qura'anic texts for grammatical evidence and how they criticized old grammarists for prioritizing the use of prose and poetry over the use of the Holy Qura'an for grammatical evidence. Contemporary grammarists also condemn how the old grammarists used grammatical rule to analyze the Holy Qura'an while excluding the Holy Qura'an as means of making grammatical rules and how they rejected some of the grammatically correct texts because they did not match their own grammatical rules.

الـهوامش

$$
\begin{aligned}
& \text { ' ينظر : النحو العربي والدرس الحديث، عبده الراجحي، دار النهضة، د.ط، 919 (م، بيروت: صب ا. }
\end{aligned}
$$

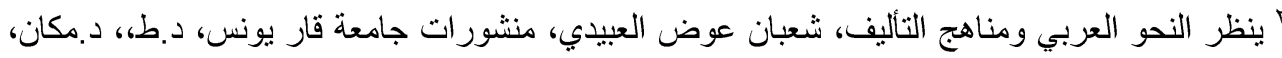

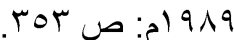

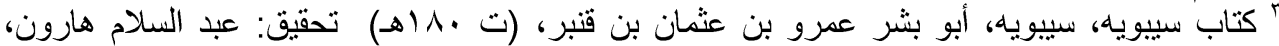

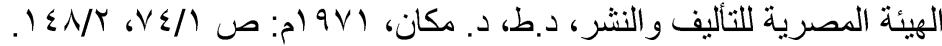

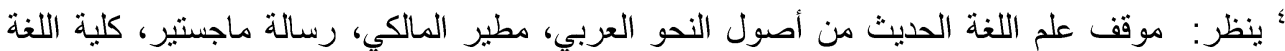

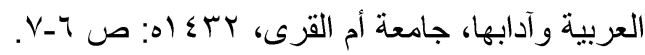

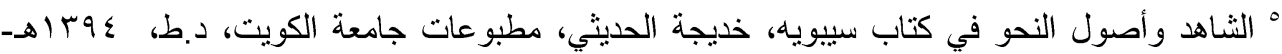

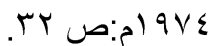

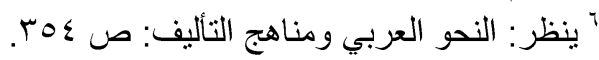

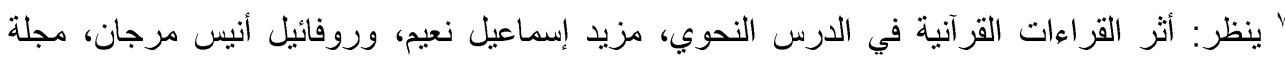

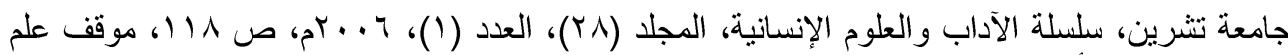

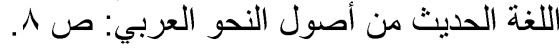

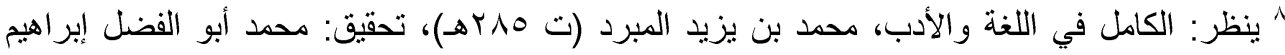

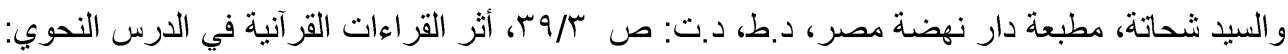

$$
\begin{aligned}
& \text { ص } 119 \\
& \text { 9 ينظر: المقتضب، أبو العباس محمد بن يزيد المبرد، تحقيق: محمد عبد الخالق عضيمة، عالم الكتب، د.ط، }
\end{aligned}
$$

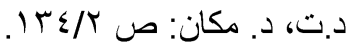




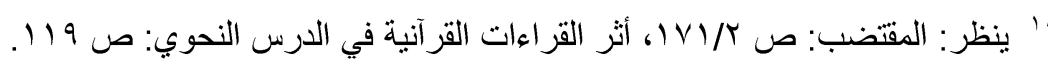

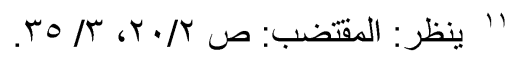

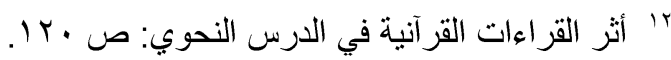

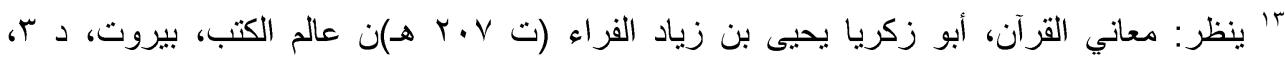

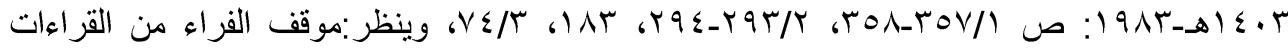

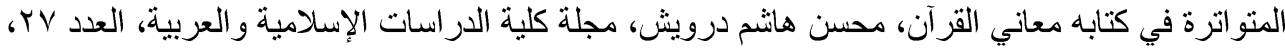

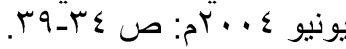

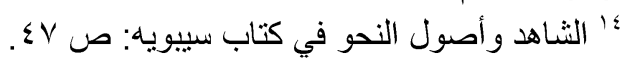

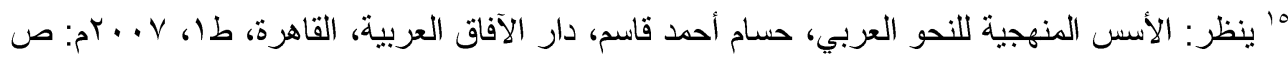

IrO-I Tr

צ' كتاب الاقتراح في علم أصول النحو، جلال الدين السيوطي (ت (19هـ) تحقيق: أحمد قاسم الحمصي

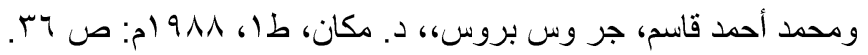

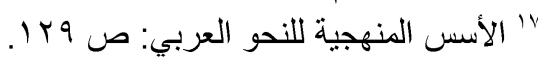

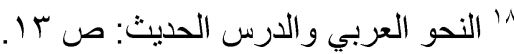

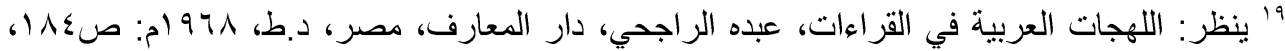

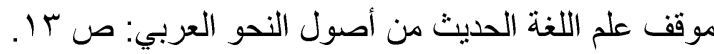

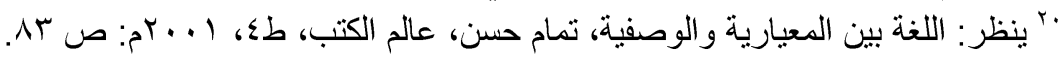

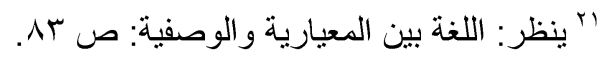

rr ينظر: القضايا الخاصة بنيسير النحو وتجديده في مصر في القرن العثرين، مصطفى زكي التوني،

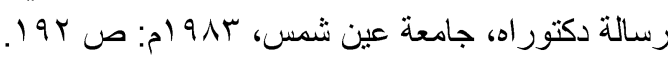

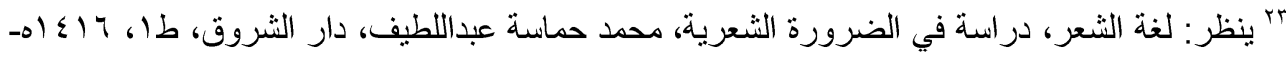

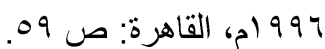

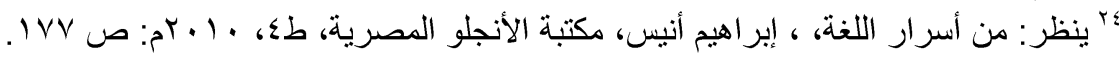

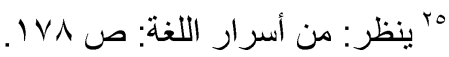

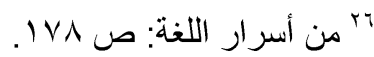

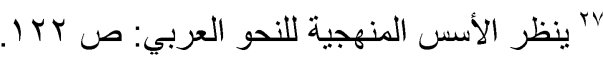

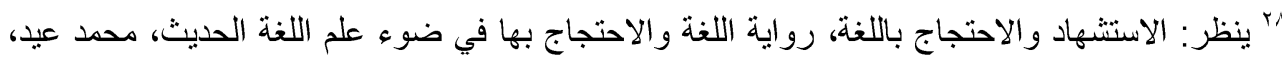

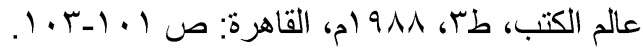

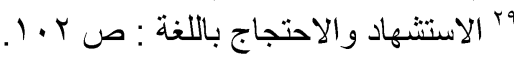

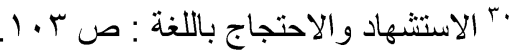

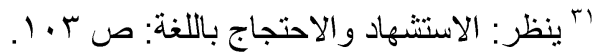

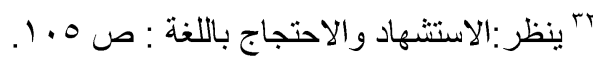

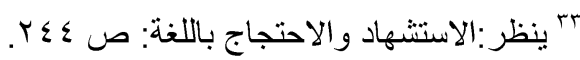

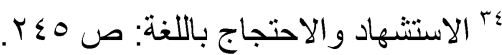

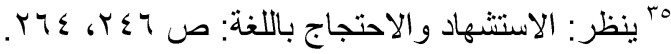




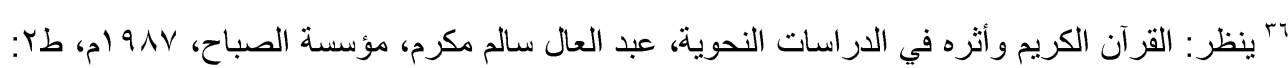
ص IV

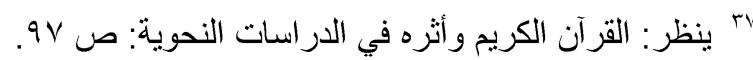

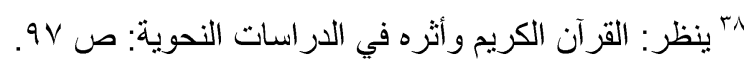

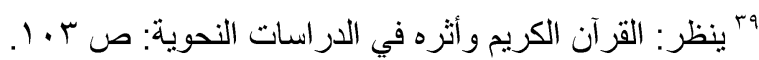

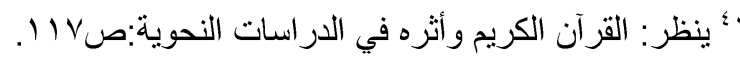

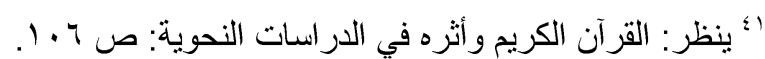

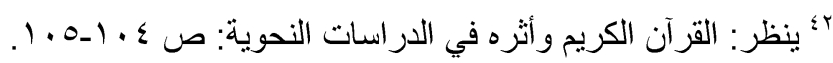

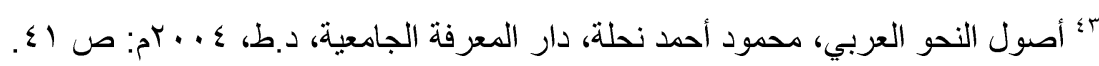

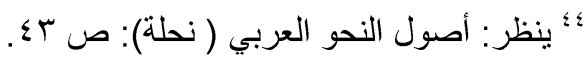

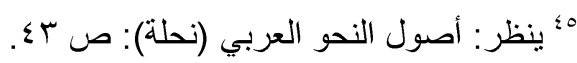

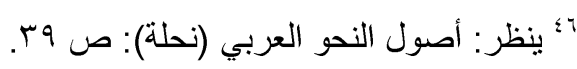

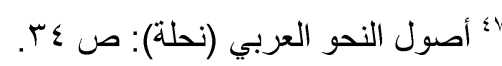

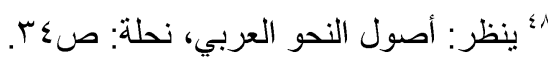

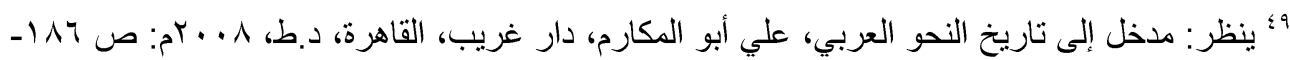
INV • أصول التفكير النحوي، علي أبو المكارم، دار غريب، القاهرة، د.ط، ج +. بام: ص ع با.

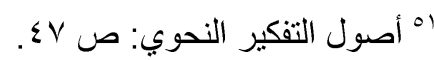

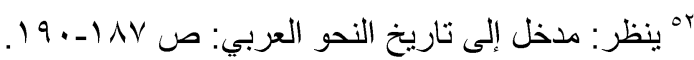

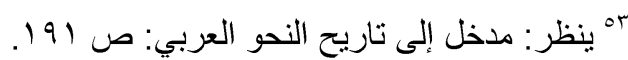

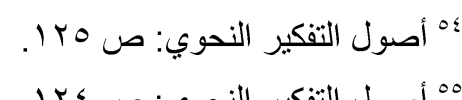

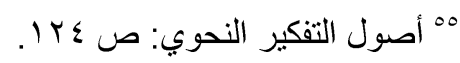
ror انظر : ص r من هذه الدراسة.

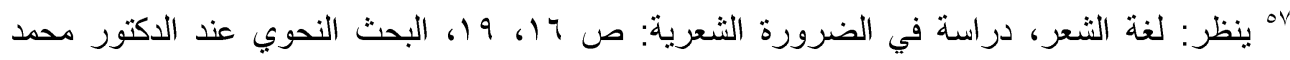

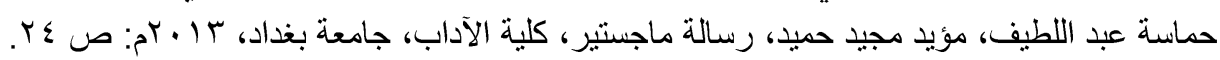

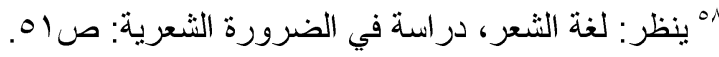

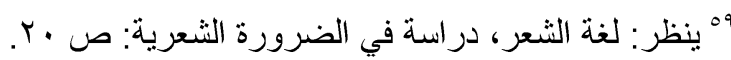

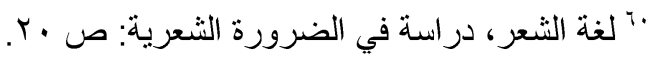

